(c) 2019 Elsevier Ltd. All rights reserved. This manuscript version is made available under the CCBY-NC-ND 4.0 license http://creativecommons.org/licenses/by-nc-nd/4.0/ 


\section{Author's Accepted Manuscript}

Exploring the role of ICT on household behavioural energy efficiency to mitigate global warming

Leire Bastida, Jed J. Cohen, Andrea Kollmann, Ana Moya, Johannes Reichl

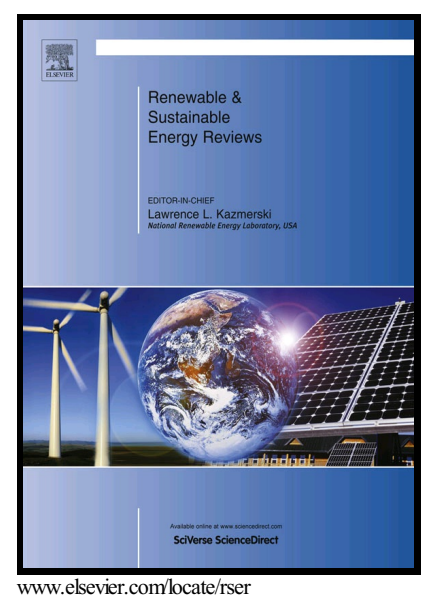

PII: $\quad$ S1364-0321(19)30007-3

DOI: $\quad$ https://doi.org/10.1016/j.rser.2019.01.004

Reference: RSER8890

To appear in: Renewable and Sustainable Energy Reviews

Received date: 11 May 2018

Revised date: 16 July 2018

Accepted date: 1 January 2019

Cite this article as: Leire Bastida, Jed J. Cohen, Andrea Kollmann, Ana Moya and Johannes Reichl, Exploring the role of ICT on household behavioural energy efficiency to mitigate global warming, Renewable and Sustainable Energy Reviews, https://doi.org/10.1016/j.rser.2019.01.004

This is a PDF file of an unedited manuscript that has been accepted for publication. As a service to our customers we are providing this early version of the manuscript. The manuscript will undergo copyediting, typesetting, and review of the resulting galley proof before it is published in its final citable form. Please note that during the production process errors may be discovered which could affect the content, and all legal disclaimers that apply to the journal pertain. 


\title{
Exploring the role of ICT on household behavioural energy efficiency to mitigate global warming
}

\author{
Leire Bastida $^{1}$ \\ Jed J. Cohen ${ }^{2 ; *}$ \\ Andrea Kollmann ${ }^{2}$ \\ Ana Moya ${ }^{1}$ \\ Johannes Reichl ${ }^{2}$
}

${ }^{1}$ Tecnalia

Parque Cientifico y Tecnologico de Bizkaia, Ed. 700

E-48160 Derio, Bizkaia, Spain

${ }^{2}$ The Energy Institute at Johannes Kepler University

Altenbergerstr. 69, 4040 Linz, Austria

* Corresponding author: cohen@energieinstitut-linz.at, +43-732-2468-5662

Conflict of interest: the authors declare that they have no conflict of interest

Keywords: ICT, energy efficiency, demand response, $\mathrm{CO} 2$ emissions, smart meters, electricity

Acknowledgements: The authors gratefully acknowledge funding from the European Union's Horizon 2020 research and innovation programme under the PEAKapp project, grant agreement No. 695945 (http://www.peakapp.eu/).

\footnotetext{
Abstract

With the advent of ICT in the energy system, new possibilities to inform and influence residential electricity consumption become available. We explore the potential of ICT-based interventions in households to decrease electricity usage, improve energy efficiency and thus contribute to reducing GHG (greenhouse gas) emissions from this sector. Based on a literature review on the subject, we suggest that ICT can affect some of the main
} 


\section{ACCEPTED MANUSCRIPT}

behaviour-influencing factors, and discuss the causal avenues by which these effects can take hold. Our review finds that ICT-based effects on consumer behavior can reduce household final electricity consumption by 0 $5 \%$. These and other findings from the literature are used to define parameter values, which reflect the efficacy of ICT at changing household energy usage patterns, and ultimately decreasing GHG emissions from the electricity sector. A quantitative analysis of the potential for ICT to contribute to reaching the $1.5^{\circ} \mathrm{C}$ target in the context of the European Union (EU) energy sector is performed. It is found that ICT-based interventions in household energy use could contribute between $0.23-3.3 \%$ of the $\mathrm{EU} \mathrm{CO}_{2} \mathrm{e}$ reduction target from the energy sector that would keep warming under $1.5{ }^{\circ} \mathrm{C}$, corresponding to $4.5-64.7$ mio. $\mathrm{tCO}_{2} \mathrm{e}$ abated per year.

Keywords : ICT, energy efficiency, demand response, $\mathrm{CO}_{2}$ emissions, smart meters, electricity

Word Count: 6,250 


\section{Introduction}

Information and communication technologies (ICT) are expected to contribute to the transition to a low-carbon electricity system by making it possible for consumers to make more efficient energy decisions [1]. The central technology in the ICT-energy sphere is the smart meter, which is a part of advanced electricity metering infrastructure that allows for measurement and storage of electricity data at high resolution (i.e. hourly or quarter-hourly) and facilitates near real-time communication of these data to consumers and utility companies. Smart meter technology enables interventions in household electricity usage such as home energy management, battery system management, distributed renewable production management, dynamic (time-variant) electricity tariffs, demand forecasting and load-shifting (demand response) [2]. These measures can optimize and increase efficiency in household electricity use, reduce grid operation costs, and ultimately reduce carbon emissions from electricity production. To increase its effectiveness smart meter infrastructure can be augmented and combined with other ICT-based solutions such as phone and computer applications, automated smart home and smart thermostat systems, and direct communication platforms between utilities and consumers.

The European Union (EU) is at the forefront of adopting ICT in the energy sector, with the goal of equipping $80 \%$ of suitable households with smart meters by 2020 [1]. In the past, European households were informed about their electricity consumption only one time per year or per month. The goal of the smart-meter-driven future is that the higher frequency of feedback may support households in adopting energy efficiency and energy conservation measures on a grander scale. It is important to note that while smart meter technology is welldeveloped, it is still subject to the inaccuracies and 'kinks' of a newer technology. For instance, Leferink et al. [3] show how electromagnetic interference can lead to inaccurate reading from smart meters. This paper takes the view that these issues are not major, and are unlikely to substantially derail the smart meter rollout and its applications.

Such increased activities will be needed to meet the challenge of achieving a decarbonised economy and especially actions taken in the building sector which accounts for about $19 \%$ of global GHG (greenhouse gas) emissions [4, p 46]. Occupant behaviour in buildings is a major factor influencing the energy-related building performance [5]. People spend more than $90 \%$ of their time in buildings [6] and their expected desired comfort level regarding indoor climatic conditions drives them to perform specific actions in order to satisfy their physical and non-physical needs, for example adjusting the thermostat settings, opening windows, or turning on lights [7]. These specific actions directly affect building conditions (e.g. indoor temperature, humidity level, air quality, etc.), thereby impacting energy consumption and energy costs. In total, the effects of these behavioural changes can lead to increases in buildings' actual energy consumption of up to $40 \%$ above what could be expected from a purely technical assessment [8].

This paper explores the potential for ICT solutions in the electricity sector to contribute to reducing carbon emissions related to households in order to mitigate global warming. We use the minimal realistic global warming goal of $1.5{ }^{\circ} \mathrm{C}$ through 2100 as a benchmark, in light of the ongoing efforts to quantify the impacts of exceeding this goal discussed in the IPCC Special report on Global Warming of $1.5^{\circ} \mathrm{C}$. The $1.5^{\circ} \mathrm{C}$ warming goal requires faster uptake of GHG abatement strategies than the $2{ }^{\circ} \mathrm{C}$ target [9]. ICT-based interventions could 
be a means of achieving reduction in GHG from the electricity sector in the near-term, as the investments needed are relatively small on a disaggregated scale (e.g. about 200 EUR for a smart meter per household). To reach the $1.5{ }^{\circ} \mathrm{C}$ goal through 2100 total atmospheric $\mathrm{CO}_{2}$ concentrations should be kept below $430 \mathrm{ppm}$ [4, p 21]. This corresponds to a decrease in anthropogenic GHG emissions of $70-95 \%$ by 2050 . The EU's Strategic Energy Technology (SET) Plan is in line with this emission reduction target by professing an EU-wide goal of 80\% reductions in GHG emissions from the energy sector by 2050 [10]. ICT solutions are expected to contribute to meeting this goal by enabling a "smart consumer-centric energy system" whereby consumers improve the flexibility and efficiency of the energy system by making more informed choices [10].

To successfully engage European citizens with the transition to a low-carbon energy system the provision of information is critical as it can influence personal norms about the environment, shape associated beliefs, and spur pro-environmental actions [11]. In the energy markets, ICT-based solutions can play a pivotal role in providing feedback and making energy flows visible [12]. The more visible information about energy consumption patterns, prices and other related aspects, the more attention it will likely receive from users, making them more aware about the impact of their actions in terms of overall comfort and energy efficiency potentials. ${ }^{1}$ The European Commission has repeatedly addressed energy savings through ICT [1, 10, 13, 14, 15] and derives three conditions needed to trigger lasting behavioural change and energy savings, which are:

i. A high level of information and communication

ii. The provision of economic incentives

iii. Supporting administrative frameworks, such as regulated dynamic tariff schemes

The first of these conditions is the core mechanism addressed with consumer information oriented ICT systems. The second channel relies on ICT as well, e.g. by providing households dynamic prices and tariffs incentivizing loadshifting towards times of high production from renewable sources. While such prices and tariffs are not primarily designed to reduce total electricity consumption, their ecological effect is potentially high when they achieve a substitution of fossil electricity generation with renewable generation. The European Environment Agency [5] assessed that behavioural change measures can deliver sustainable savings of between 5\% and 20\% of total energy demand. These benefits come on top of the energy efficiency improvements that can be achieved by technological measures.

A primary goal of our paper is to assess the potential for ICT driven behavioural change to contribute to reductions in electricity usage and ultimately GHG emissions. Section 2 discusses the theoretical and behavioural avenues through which ICT can influence consumer energy choices. Section 3 then reviews the empirical evidence regarding the effect of ICT on household electricity choice and consumption in pilot tests. The review of empirical studies is used to inform our own quantitative analysis of the potential for ICT-based solutions to reduce GHG emissions from household electricity use in the EU. The findings from our quantitative analysis are then generalized to the global case, and compared with the necessary global GHG emission reductions in order to keep global warming under $1.5{ }^{\circ} \mathrm{C}$. To conclude, we infer from the literature review and our own quantitative analysis the potential for ICT-solutions to contribute to keeping global warming under 1.5 ${ }^{\circ} \mathrm{C}$.

\footnotetext{
${ }^{1}$ Up to a reasonable saturation point, which has not yet been approached.
} 


\section{ICT and consumer behaviour}

In general, user behaviour related to energy use is influenced by four factors: economic considerations, values, attitudes and norms, and practical aspects of daily life [16]. In order to change energy consumption behaviour, routines and habits need to be changed and users need to be made aware of the consequences of their daily energy use. There are three factors that can be used to encourage lasting behavioural change in consumers [17]:

- Motivating factors: individual, internal drivers of behaviour. Such factors are awareness, knowledge, social influence, attitude, perceived capabilities and intention. For people to intentionally change their energy behaviour, they must become aware of their energy use, pay notice to it, and be informed about the consequences. They must then be motivated to use the available information and instruments to control their energy use.

- Reinforcing factors are consequences of actions that give individuals positive or negative feedback for continuing their behaviour. Such factors include information about the impacts of past behaviour, feedback of peers, advice, and feedback by powerful actors.

- Enabling factors are the external constraints on behaviour. These factors allow new behaviour to be realised.

Considering these three categories of factors we note that ICT-based approaches would be appropriate as motivating and reinforcing factors. ICT can be used to supply feedback on a person's energy consumption, show them benchmarks and usage targets, and reinforce behaviour by showing them their monetary or carbon savings.

Darby [18] and Hargreaves [19] show that providing users real-time data about energy consumption in buildings helps change their behaviour. When energy end-users have an appropriate and understandable reference frame, they are empowered to determine whether their energy consumption is excessive or not. Using timely feedback measures will increase the users' awareness of energy consumption while keeping them motivated. The type of feedback and information provided strongly influences the efficacy of such feedback [20]. A current, productive vein of research is to define the optimal feedback strategy and test its application.

The European Union issued Directives 2009/72/EC, 2009/73/EC, and Directive 2012/27/EC that insist on making smart meters available to the majority of households in the EU by 2020. Smart meters collect the electricity consumption of households in a high frequency (i.e. quarterly or hourly values) and transmit these figures to a data hub. The detailed consumption data may then be forwarded to the consumers, and used to motivate them to save energy by better understanding the impact of their behaviour and related financial benefits [21].

Forwarding households their electricity consumption data in and of itself may not be a very effective strategy as it is difficult for consumers to interpret their load profiles and derive conclusions for improving their energy efficiency. This is especially true in cases where new tariff structures are applied, as consumers may have little understanding of how they can optimize their consumption under such tariffs. For instance, in the case of peak 
demand tariffs ${ }^{2}$ research has shown that consumers have only a very basic understanding of the peak demand concept and how it can be used to reduce grid costs and electricity costs in a household [22].

Similarly, while people usually know the number of electric devices they own and the primary generation source of the electricity they use, they have little understanding of the energy consumption from these devices [21]. However, with the ascent of smart phones and mobile internet connections, smart phone and computer apps may provide an accessible platform for triggering energy efficiency by exploiting energy consumption data from smart meters in a motivating and incentivizing manner. Using smart phones and tablets as one-stop platforms for the provision of related information to households is a promising potential for motivating households to improve their energy usage. Such applications can combine energy consumption information with game elements and further motivational mechanisms, such as comparison with other consumers, to trigger lasting behavioural change [23].

Efforts to rollout smart meters and other energy-related ICT products are not without complications. Foremost among them is getting consumers to accept new ICT technology and to use it on a consistent basis [24, 25]. In terms of accepting smart technology, Richter and Pollitt [26] study the willingness of consumers to accept smart meter services and contracts, including the necessary sharing of personal data with electricity companies. The authors built a discrete choice experiment that was completed by 1,892 UK residents. The results of the experiment shows that generally consumers will demand considerable compensation to participate in smart electricity and automated demand response programs. Pricing strategies to incentivize consumers to participate in smart meter programs and target groups of consumers are explored. In particular, the authors suggest a combination of fixed and transaction-based payments would result in increased acceptance of smart meter programs and that strong data privacy services would reduce the total payments required.

Getting consumers to engage with the ICT product could be accomplished through integration with social networks and gamification of the ICT. The usage of social networks has been found to be highly successful at achieving long-term behavioural change in other fields, such as education and sports [27]. Gamification, the use of game mechanics to drive engagement, is a reinforcing factor that has been shown to encourage targeted behaviours with instant positive feedback [28]. The progression and interaction supplied by gamification has the potential to alter long-term behaviour and motivate electricity consumers [29, 30, 31]. However, not everyone is motivated through competition and quantifying actions and assigning virtual rewards can backfire with unintended consequences that lead to an increase in unethical behaviour or reduced motivation [32, 33, 34]. Research into user experience and interface design suggests that the more time and effort developers spend on creating, testing and refining the most attractive gaming system for user, the higher the user's motivation to engage with the system will be $[35,36]$. Further research develops the concept of 'meaningful gamification', to separate intrinsic and extrinsic motivation and to develop intrinsically motivating solutions through which the participants can carry out their activity more effectively $[37,38,39]$. Where gamification fails to produce results, a disregard for user-centric design and lack of motivating factors may be to blame [40]

\footnotetext{
${ }^{2}$ Peak demand tariffs are a promising tariff structure for reducing grid costs where consumers are charged based on their maximum usage over a time frame.
} 
Overall, while ICT has proven to be an effective tool at increasing the awareness of households towards energy issues and their ability to make more informed energy choices, the specifics of ICT adaptation to this role are still undergoing intensive research. The challenges of smart technology acceptance, motivating behavioural change, and proper feedback mechanisms are particularly important to overcome in the near future for ICT to be able to contribute substantially to a low-carbon energy system.

\section{Effects of ICT on household electricity consumption}

We review the literature that has estimated the effects of ICT on household electricity consumption in order to inform our quantification of the potential reduction in GHG emissions from improvements in household energy efficiency. The European Commission has repeatedly addressed energy savings expectations from household use of energy-related ICT [13, 14]. Estimates from the European Commission [41] find that household electricity consumption can be reduced by up to $20 \%$ from behavioural change including energy efficient appliances. The American Council for an Energy-Efficient-Economy found that total energy savings of $22 \%$ were feasible for U.S. households [42]. Herein we discuss how ICT can contribute to realizing these savings, and estimate the contribution that ICT can make based on past literature.

Following The European Commission [13, 14], Latiner and Ehrhardt-Martinez [42], and Trotta [43] we define the ways in which energy-related ICT can affect household electricity use as:

1) Behavioural change

a. Appliance-based energy efficiency improvements

b. Reducing overall electricity consumption

c. Shifting electricity loads

2) Directly via home-automation systems that optimize energy use

The first category, behavioural change, takes place when households willingly shift their energy consumption patterns in response to information or benchmarking from an ICT platform. We identify three types of behavioural change: appliance based savings, reduction in total energy consumption, and loadshift (or demand response), where consumers change the times they use energy. The second category encompasses the smart home and smart thermostat concepts, where household electricity use is automatically optimized to satisfy the needs of the household and potentially reducing electricity use.

Under the aegis of behavioural change, households can alter their purchasing decisions to choose energy efficient appliances to replace old appliances. An example of appliance based energy savings is a household upgrading their washer to a more energy efficient model, or replacing light bulbs with more efficient varieties. Previous research has shown that energy efficiency upgrades of these types are much more likely to be applied by households with higher levels of education and income [44, 45]. In a comprehensive study of energy savings potentials across the EU-27, Eichhammer et al. [46] estimate the potential for increased energy efficiency in household appliances. We refer to their estimates for the year 2020, as these most-nearly reflect the current situation and are less reliant on their assumptions of future technological progress in appliance technical efficiency. Eichhammer et al. [46] find that household electricity consumption can decrease by 5.8-21.9\%, with a 
middle value of $9.9 \%$, depending on the speed of market uptake and the government policies that are in place. ${ }^{3}$ While ICT can be used to motivate households to buy more efficient appliances, not all of the estimated reduction in electricity use would be due to ICT-based effects. To account for this we use only the middle value from Eichhammer et al. [46] of 9.9\% and perform sensitivity analysis around our assumption of the proportion of electricity savings that will be due to ICT. We use values of 10\%, 25\%, and 50\%, for this assumption, which leads to values of $4.95 \%, 2.475 \%$, and $0.99 \%$, which we call our optimistic, middle and pessimistic range of values, respectively, for the potential energy savings from appliances due to ICT-based effects reflected in Table 1. Note that improvements in energy efficiency are subject to a rebound effect since the fact that appliances are now cheaper to operate may lead to more appliance usage by households or increases in other purchases [47]. Though researchers have found that this effect will most likely not negate reduction in electricity demand from energy efficiency, it is likely to decrease the overall effect of energy efficiency investments [48]. Our conservative estimates of the potential energy savings from appliances due to ICT also reflect the possible rebound effect.

The reduction of overall energy consumption from behavioural change attributable to ICT-provided feedback, such as that from in-home smart meters, has garnered significant attention in energy research [e.g. 20, 49, 50]. However, the reduction in energy consumption that can be expected from additional information varies strongly between studies [20]. An empirical review of these results was completed in 2013, and found that the average estimated reduction in household energy use from the provision of energy consumption feedback was $7.4 \%$ across the 156 studies surveyed [49]. However, of these 156 studies only 22 were robust to respondent sociodemographic, geographic, and climate differences. The 22 robust studies showed an average energy reduction of $2 \%$ due to increased information. A more recent, similarly robust study, conducted in Linz, Austria, showed that providing smart meter users with effective feedback related to their energy consumption reduced energy use by 5\% [50]. This effect was attributed to habitual changes including changes in appliance usage. In a separate review of past literature, the authors take a more pessimistic view and argue that there may be no medium to long-term reductions in energy use from ICT-based information provision [20]. Furthermore, the type of feedback and information provided strongly influences the level of energy-use-reduction achieved [20].

Dynamic tariffs supplied via ICT may also decrease overall electricity consumption. Stromback et al. [51] and Hillemacher et al. [52] assessed the effects of semi-dynamic tariffs in large field tests and showed that households saved an additional $2.5 \%$ and $2.6 \%$ of their baseline energy consumption, in Ireland and Austria respectively. It is not yet clear how dynamic tariffs interact with additional information, for instance if these effects are additive, but for our "optimistic" scenario we assume some additivity and include the effects of dynamic tariffs in the quantification of ICT-driven electricity savings. Current large-scale field tests are underway to assess the interactions between dynamic tariffs and increased consumer information [23].

The potential of ICT-induced loadshifting, or demand response, to reduce carbon emissions from energy production is based on the premise that consumption during periods of high demand will be substituted with consumption during periods of lower demand and higher renewable generation. This would enable systemic energy efficiency to be improved, and would decrease the associated GHG emissions significantly. However, it

\footnotetext{
${ }^{3}$ See Table 6.6 on page 78 of the Eichhammer et al [46] Final Report.
} 
is unclear if this dynamic will consistently hold true such that loadshifting will decrease carbon emissions from energy use on the aggregate [53,54]. The certain environmental value of loadshifting lies in its ability to enable an electricity grid that relies heavily on renewable generation though balancing intermittent supply with demand [55]. Such effects of loadshifting have been shown to lower consumer electricity bills, and reduce price volatility in electricity markets $[56,57]$. This is not equivalent to saying that households shifting load to off-peak times in and of itself will reduce carbon emissions, which is the effect we are interested in here.

The direct effect of loadshifting on overall carbon emissions is based on the electricity mix of the regional grid, and particularly the amount of renewables in the grid and when these renewables produce electricity compared to peak electricity usage [58]. As such, there is strong regional heterogeneity in the expected effect of loadshifting on carbon output from the electricity sector. Specifically, regions that have high levels of renewable resources that can be dispatched during off-peak hours can see reductions in annual $\mathrm{CO}_{2}$ emissions between 0 and 600,000 tonnes per GW demand response dispatched to meet peak load [54]. In the case of South Africa loadshifting was estimated to reduce $\mathrm{CO}_{2}$ emissions by $91 \mathrm{~kg}$ per MWh shifted, which amounts to about a $10 \%$ reduction in $\mathrm{CO}_{2}$ emissions per MWh [59]. Due to the relative abundance of low-carbon electricity sources in Europe we suggest that $\mathrm{CO}_{2}$ reduction due to loadshift could be higher for this continent. As a high-end, "optimistic" estimate of this potential we assume that every kWh consumed during off-peak periods has $25 \%$ of the $\mathrm{CO}_{2}$ compared to an average $\mathrm{kWh}$ of electricity based upon Moomaw et al. [60]. Given the paucity of literature on the effects of loadshifting on carbon output we use a range of informed parameter values and perform a sensitivity analysis to complete our analysis of the $\mathrm{CO}_{2}$-reduction potential of ICT in the European electricity system.

In terms of the potential for households to shift their electricity loads to off-peak hours and realize this reduction in $\mathrm{CO}_{2}$ emissions we use a middle value of loadshift potential of $10 \%$ of annual energy demand based on the review completed by Moser et al. [61]. The lower end value is 5\%, which comes from the study of Nilsson et al. [62], who showed that ICT-based price visuals induced Swedish households to shift demand from peak to offpeak times. Our high-end value for loadshift potential comes from Smith and Brown [54], who use a value of $17 \%$ in their analysis of loadshifting and carbon emissions.

The second main category, home automations, are usually designed with the primary target of increasing the household's comfort level. Functionalities frequently address, for example, the automatic adjustment of sunblinds to the intensity of solar radiation, or the combined dimming of lights, playing of pre-selected music tracks and control of other ambient related equipment through pre-settings. However, home automation systems can effectively support the energy efficiency of a building through controlling the heating system, or synchronizing the electricity consumption with rooftop photovoltaic production. Nevertheless, as comfort usually is the primary motivation for installing home automation, energy savings potentials may lag behind. A combination of home automation systems and a consumer information oriented ICT system, at best as a one-stop system, can increase energy savings through more frequent and comprehensive utilization. In one case, a fully optimized home built specifically to interface with smart home technology achieved energy savings of 37\% [63]. In a U.S. study, it was estimated that an optimized smart thermostat can save up to $28 \%$ of the electricity normally used for heating and cooling [64]. However, this result was not tested in an application to homes. Similarly, Meyers et al [65] show that in theory 39\% of household energy use is wasted and that this same amount could be saved using ICT-enabled monitoring and control technologies. Finally, Cosar-Jorda et al. [66] 
use data from 11 UK homes to show that household energy demand could be reduced by 50-70\% if all of their potential interventions in household behaviour, retrofits and replacement were applied. However, all of these studies lack currently-implementable solutions that are proven by empirical evidence on a large-scale, making it difficult to assess the potential of ICT-based smart home concepts for contributing to carbon reduction on the aggregate. Current rates of home automation systems are low across Europe ${ }^{4}$, and the effects of home automation are likely to be duplicative of behavioural changes. Thus, we do not include estimates of energy savings to this last category of motivational channels in our quantitative assessment.

Table 1: Parameter values for the potential effect of ICT on household electricity behaviours used in the quantitative assessment

\begin{tabular}{|c|c|c|c|c|}
\hline \multirow[t]{2}{*}{ Estimates: } & \multicolumn{2}{|c|}{$\begin{array}{l}\text { Behavioural change reduction in total } \\
\text { household electricity consumption }\end{array}$} & \multicolumn{2}{|c|}{$\begin{array}{l}\text { Appliance-based reduction in total } \\
\text { household electricity consumption }\end{array}$} \\
\hline & Source & Value & Source & Value \\
\hline Optimistic & [50] [51] [52] [49] & $\begin{array}{l}5 \% \text { reduction } \\
\text { (combined effect of } \\
\text { behavioural change } \\
\text { and dynamic tariffs) }\end{array}$ & $\begin{array}{l}\text { Assumed }{ }^{*} 50 \% \text { of } \\
\text { benefits from ICT }\end{array}$ & $4.95 \%$ reduction \\
\hline Middle & [49] & $2 \%$ reduction & $\begin{array}{l}\text { Assumed } 25 \% \text { of } \\
\text { benefits from ICT }\end{array}$ & $2.475 \%$ reduction \\
\hline Pessimistic & [20] & $0 \%$ reduction & $\begin{array}{l}\text { Assumed }{ }^{*} 10 \% \text { of } \\
\text { benefits from ICT }\end{array}$ & $0.99 \%$ reduction \\
\hline \multirow[t]{2}{*}{ Estimates: } & \multicolumn{2}{|c|}{ Household loadshift potential } & \multicolumn{2}{|c|}{$\begin{array}{l}\text { Decrease in } \mathrm{CO}_{2} \text { emissions per unit load } \\
\text { shifted }\end{array}$} \\
\hline & Source & Value & Source & Value \\
\hline Optimistic & [54] & $\begin{array}{l}17 \% \text { loadshift from } \\
\text { peak to off-peak }\end{array}$ & $\begin{array}{l}\text { Assumed value based } \\
\text { on [60] }\end{array}$ & $25 \%$ \\
\hline Middle & $\begin{array}{l}\text { Assumed value based } \\
\text { on [61] }\end{array}$ & $\begin{array}{l}10 \% \text { loadshift from } \\
\text { peak to off-peak }\end{array}$ & [59] & $10 \%$ \\
\hline Pessimistic & [62] & $\begin{array}{l}5 \% \text { loadshift from } \\
\text { peak to off-peak }\end{array}$ & {$[54]$} & $0 \%$ \\
\hline
\end{tabular}

Note: Most values are based on empirical research, where field tests have been completed. Values that are defined "assumed" are not directly from empirical evidence, but involve some assumptions based on literature, or simulation models.

*Eichhammer et al. [46] estimate that household appliance updates contribute a 9.9\% reduction of electricity use in their 2020 "high-policy intensity" scenario. We adjust these values based on an assumed proportion of this decrease that is attributable to ICT.

Table 1 shows the parameter values that we have pulled from the literature, or assumed based on literature, which will inform our quantitative analysis in the next section. We establish a range of values for each parameter from "optimistic" to "pessimistic" to reflect the uncertainty about the final form and efficacy of ICT applications and some divergent research findings. Our chosen range of parameter values matches the expectations of the EU Commission Smart Grids Taskforce who estimated an expected decrease in energy savings between $0 \%$ and $5 \%$ across 16 EU nations. These figures include behavioural change and loadshifting effects, but only for the application of smart meters and do not include the potential of other ICT-technologies [1].

\section{Quantitative Analysis}

In this section, we estimate the potential effects of ICT-based interventions on household electricity use and subsequent GHG across the EU-28, expressed as $\mathrm{CO}_{2}$-equivalent $\left(\mathrm{CO}_{2} \mathrm{e}\right)$ emissions. We use the EU as an

\footnotetext{
${ }^{4}$ Statista [67] estimates a penetration rate of smart home systems in Europe of 5.2\% in 2017.
} 
illustrative since, in many ways, the EU is leading the global push for de-carbonization of the energy system. Consequently, much of the research and many of the field tests which explore the role of ICT in influencing consumer electricity choices is based in the EU. We expect that as other nations and regions follow the EU towards a de-carbonized energy system the potential for ICT to aid the transition in these regions will be similar to what has been shown for the EU.

This quantification should be taken as a case study and starting point for the much-needed comprehensive research into the realistic potentials for new technologies to contribute to GHG reduction. As such, it is subject to numerous assumptions and uncertainties discussed in Sections 3 and 4, which are reflected in the sensitivity analysis. The scenario assessed is one where empirically-proven ICT-based interventions in energy are spread to all households and are assumed to be functioning as designed.

We build data on the electricity consumption per household at the country level based on Eurostat data, including total household electricity consumption (code tsdpc310), population (code demo_pjan), and average persons per household (code ilc_lvph01). Data from the year 2015 was used, as it is the most recent data with no missing values. We use a static baseline situation where climate variables and technological progress are assumed to remain constant, due to the potentially impactful assumptions required for building dynamic baselines [68]. Thus in relation to future climate targets, our quantification shows the current potential of ICT to contribute to these targets. This is thus a conservative route, as ICT methods for interfacing with households are likely to improve as may the overall energy efficiency of appliances [see e.g. 20, 46]. For every country the national energy mix factor of electricity production, available from Covenant of Mayors [69], was used for translating the energy savings into reductions in $\mathrm{CO}_{2} \mathrm{e}$ emissions.

Table 2 shows our quantification strategy and the results for the estimation based on all the "middle value" parameters that are presented in Table 1. We interpret the results of the $\mathrm{CO}_{2} \mathrm{e}$ abatement potential from ICT from the quantitative analysis in relation to the total required emissions reductions needed to keep global warming below $1.5{ }^{\circ} \mathrm{C}$. Specifically the IPCC estimates that humankind will need to reduce GHG emissions by $70-95 \%$ by 2050 in order to hit this climate target [4, p 21]. For the EU to do its part in hitting this target it will need to succeed in reducing GHG emissions by a similar amount, which is reflected in the SET Plan goal of an $80 \%$ reductions in GHG emissions from the energy sector by 2050 [10]. Annual total emissions in the EU-28 are 4,451.8 mio. $\mathrm{tCO}_{2} \mathrm{e}$ (million tons of $\mathrm{CO}_{2}$ equivalent) according to 2015 Eurostat data. Emissions were at 5,700 mio. $\mathrm{tCO}_{2} \mathrm{e}$ in 1990, showing the EU's success at reducing emissions over this time period. In 2015, about 55\% of EU-28 emissions were related to the energy sector, which amounts to 2,448.6 mio. $\mathrm{tCO}_{2} \mathrm{e}$ emitted by the energy sector in this year. Taking this figure as the baseline, the targeted reductions by 2050 are $80 \%$ of $2,448.6$ mio. $\mathrm{tCO}_{2} \mathrm{e}$ or $1,958.4$ mio. $\mathrm{tCO}_{2} \mathrm{e}$ annual abatement from the energy sector.

Looking first at the results of the country-wise quantification in Table 2 we see heterogeneity across EU-28 nations in terms of the per household quantity of $\mathrm{CO}_{2} \mathrm{e}$ emissions that are able to be abated due to ICT-based household interventions. This heterogeneity is driven exclusively by the differing electricity consumption and emission factors in each nations, where a higher emission factor indicates more $\mathrm{CO}_{2} \mathrm{e}$ intensity in electricity production, as the parameter values relating ICT to household energy decisions are the same across nations. 
Thus, nations with higher per household energy usage and/or higher emissions factors are able to abate more emissions through ICT.

We have aggregated the data shown in Table 2 across EU-28 nations for indicators of interest, and then repeated the process for the ranges of parameter values shown in Table 1, namely the "optimistic" and "pessimistic" sets of parameter values. The aggregated results are shown in Table 3. We see from Table 3 that the total potential contribution of ICT-based interventions on household electricity usage to $\mathrm{CO}_{2} \mathrm{e}$ reduction across the EU-28 is in the range of 4.5-64.7 mio. $\mathrm{tCO}_{2} \mathrm{e}$ per year, with a middle estimate of 24.9. This represents 0.23-3.3\% of the EU target of $\mathrm{CO}_{2} \mathrm{e}$ reduction from the energy sector to keep warming under $1.5{ }^{\circ} \mathrm{C}$. The percent of this target from the middle estimate is $1.22 \%$, which is again based off a reductions target of 1958.4 mio. $\mathrm{tCO}_{2} \mathrm{e}$ not emitted from the energy sector.

Using the EU as a leading case, we can then generalize our quantification to the global level. Global anthropogenic GHG emissions were about $49 \mathrm{GtCO}_{2} \mathrm{e}$ (gigatonnes $\mathrm{CO}_{2}$ equivalent) per year and about $25 \%$ of this comes from the energy sector [4]. Taking an emission reduction of $80 \%$ by 2050 as the target to reach the $1.5{ }^{\circ} \mathrm{C}$ warming goal implies that the global energy sector needs to reduce $\mathrm{GHG}$ emissions by $9.8 \mathrm{GtCO}_{2} \mathrm{e}$. Extrapolating the potential effect of ICT found for the EU globally, suggests that ICT-based interventions in household electricity use could reduce annual $\mathrm{CO}_{2} \mathrm{e}$ emissions by 0.023-0.32 $\mathrm{GtCO}_{2} \mathrm{e}(23-320$ mio. tCO $\mathrm{t})$. This extrapolation is based on the assumptions that: ICT-based interventions have similar efficacy to what has been shown in the EU across the globe, that these interventions are spread to all households, and that ICT and energy efficiency technology level remains constant.

Table 2: Country-specific calculation of per household CO2-reduction potential from ICT-based effects on electricity consumption

\begin{tabular}{|c|c|c|c|c|c|c|c|c|}
\hline Country & $\begin{array}{c}\text { Electricity } \\
\text { consumption } \\
\text { per household }\end{array}$ & $\begin{array}{l}\text { Emission } \\
\text { factor for } \\
\text { consumed } \\
\text { electricity* }\end{array}$ & $\begin{array}{c}\text { Electricity saved } \\
\text { per household } \\
\text { due to } \\
\text { behavioural } \\
\text { changes }\end{array}$ & $\begin{array}{c}\text { Electricity } \\
\text { saved per } \\
\text { household } \\
\text { due to } \\
\text { efficient } \\
\text { appliances }\end{array}$ & $\begin{array}{c}\text { Electricity } \\
\text { load shifted } \\
\text { to off-peak } \\
\text { times }\end{array}$ & $\begin{array}{c}\mathrm{CO}_{2} \mathrm{e} \\
\text { reduced by } \\
\text { behavioral } \\
\text { change and } \\
\text { appliances }\end{array}$ & $\begin{array}{c}\mathrm{CO}_{2} \mathrm{e} \\
\text { reduced by } \\
\text { loadshift }\end{array}$ & TOTAL \\
\hline & [in kWh/a] & {$\left[\mathrm{kg} \mathrm{CO}_{2} \mathrm{e} / \mathrm{kWh}\right]$} & [in kWh/a] & [in kWh/a] & [in kWh/a] & {$\left[\mathrm{kg} \mathrm{CO}_{2} \mathrm{e} / \mathrm{a}\right]$} & {$\left[\mathrm{kg} \mathrm{CO}_{2} \mathrm{e} / \mathrm{a}\right]$} & {$\left[\mathrm{kg} \mathrm{CO}_{2} \mathrm{e} / \mathrm{a}\right]$} \\
\hline Austria & 4,548 & 0.31 & 90.95 & 112.55 & 454.76 & 63.09 & 14.10 & 77.18 \\
\hline Belgium & 3,874 & 0.40 & 77.47 & 95.87 & 387.35 & 69.68 & 15.57 & 85.25 \\
\hline Bulgaria & 3,672 & 0.91 & 73.45 & 90.89 & 367.25 & 148.89 & 33.27 & 182.17 \\
\hline Cyprus & 4,769 & 1.02 & 95.37 & 118.03 & 476.87 & 217.45 & 48.59 & 266.05 \\
\hline $\mathrm{CZ}$ & 3,283 & 0.80 & 65.67 & 81.26 & 328.34 & 117.84 & 26.33 & 144.17 \\
\hline Denmark & 3,617 & 0.76 & 72.34 & 89.53 & 361.72 & 123.02 & 27.49 & 150.51 \\
\hline Estonia & 2,890 & 1.59 & 57.79 & 71.52 & 288.95 & 205.98 & 46.03 & 252.01 \\
\hline Finland & 7,674 & 0.42 & 153.48 & 189.93 & 767.40 & 143.55 & 32.08 & 175.62 \\
\hline France & 5,081 & 0.15 & 101.63 & 125.77 & 508.15 & 33.20 & 7.42 & 40.62 \\
\hline Germany & 3,187 & 0.71 & 63.74 & 78.88 & 318.69 & 100.69 & 22.50 & 123.19 \\
\hline Greece & 4,173 & 1.17 & 83.46 & 103.28 & 417.31 & 217.93 & 48.70 & 266.63 \\
\hline Hungary & 2,524 & 0.68 & 50.48 & 62.47 & 252.40 & 76.58 & 17.11 & 93.69 \\
\hline Ireland & 4,620 & 0.87 & 92.40 & 114.34 & 462.00 & 179.87 & 40.19 & 220.06 \\
\hline Italy & 2,613 & 0.71 & 52.27 & 64.68 & 261.34 & 82.80 & 18.50 & 101.30 \\
\hline Latvia & 2,109 & 0.56 & 42.17 & 52.19 & 210.86 & 53.12 & 11.87 & 65.00 \\
\hline Lithuania & 2,078 & 0.17 & 41.57 & 51.44 & 207.83 & 16.18 & 3.62 & 19.80 \\
\hline Luxembourg & 4,321 & 0.79 & 86.43 & 106.95 & 432.13 & 152.77 & 34.14 & 186.91 \\
\hline Malta & 4,009 & 0.70 & 80.18 & 99.23 & 400.91 & 125.59 & 28.06 & 153.65 \\
\hline Netherlands & 4,548 & 0.72 & 90.96 & 112.56 & 454.80 & 145.72 & 32.56 & 178.29 \\
\hline Poland & 2,083 & 1.19 & 41.66 & 51.55 & 208.28 & 110.45 & 24.68 & 135.13 \\
\hline Portugal & 2,871 & 0.75 & 57.42 & 71.05 & 287.09 & 96.35 & 21.53 & 117.89 \\
\hline Romania & 1,637 & 1.08 & 32.74 & 40.52 & 163.72 & 79.42 & 17.75 & 97.16 \\
\hline Slovakia & 2,603 & 0.35 & 52.06 & 64.42 & 260.29 & 41.12 & 9.19 & 50.30 \\
\hline Slovenia & 3,888 & 0.60 & 77.76 & 96.22 & 388.78 & 104.74 & 23.40 & 128.14 \\
\hline Spain & 3,765 & 0.64 & 75.31 & 93.19 & 376.54 & 107.67 & 24.06 & 131.73 \\
\hline
\end{tabular}




\begin{tabular}{|l|c|c|c|c|c|c|c|c|}
\hline Sweden & 8,914 & 0.08 & 178.28 & 220.62 & 891.39 & 31.51 & 7.04 & 38.55 \\
\hline UK & 3,852 & 0.66 & 77.03 & 95.33 & 385.16 & 113.41 & 25.34 & 138.76 \\
\hline AVERAGE & 3,822 & 0.70 & 76.45 & 94.60 & 382.23 & 109.58 & 24.49 & 134.07 \\
\hline
\end{tabular}

*The emissions factors for Malta and Luxembourg are based on their country specific energy efficiency reports from 2011.

Table 3: Total potential effects of ICT on household electricity use across the EU-28

\begin{tabular}{|l|c|c|c|}
\hline \multirow{2}{*}{ Parameter Values } & $\begin{array}{c}\text { Total electricity } \\
\text { shifted to off } \\
\text { peak times }\end{array}$ & $\begin{array}{c}\text { Total Electricity } \\
\text { Saved }\end{array}$ & $\begin{array}{c}\text { Total emmission } \\
\text { reduction }\end{array}$ \\
\cline { 2 - 4 } & {$[$ in TWh/a] } & {$[$ in TWh/a] } & [mio. tonnes $\left.\mathrm{CO}_{2} \mathrm{e} / \mathrm{a}\right]$ \\
\hline Middle Values & 80.15 & 35.87 & 24.94 \\
\hline Optimistic Values & 136.25 & 79.75 & 64.69 \\
\hline Pessimistic Values & 40.07 & 8.01 & 4.56 \\
\hline
\end{tabular}

Parameter values defined in Table 1

\section{Conclusion}

This paper investigates the potential for ICT-based interventions to decrease energy usage and improve energy efficiency in households. The behavioural literature on the subject, summarized in Section 2, suggests that ICT can affect two main behaviour-influencing factors, motivating and reinforcing factors, and discusses the causal avenues for this effect to take hold. In Section 3, we synthesize the literature that has estimated the magnitude of the effect of ICT on various aspects of household energy behaviour. The findings of past literature are used to define parameter values, which reflect the efficacy of ICT at changing household energy usage patterns, and ultimately decreasing $\mathrm{CO}_{2} \mathrm{e}$ emissions from the electricity sector. Utilizing the range of parameter values, we complete a quantitative analysis of the potential for ICT to contribute to reaching the $1.5^{\circ} \mathrm{C}$ target in the context of the EU energy sector. The EU case is generalized to the World's economy based on various assumptions. We find that ICT could contribute between $0.23-3.3 \%$ of the $\mathrm{EU} \mathrm{CO}_{2} \mathrm{e}$ reduction target from the energy sector that would keep warming under $1.5{ }^{\circ} \mathrm{C}$. This corresponds to 4.5-64.7 mio. $\mathrm{tCO}_{2} \mathrm{e}$ abated per year, with a middle estimate of 24.9, in the EU case, and 23-320 mio. $\mathrm{tCO}_{2} \mathrm{e}$, with a middle estimate of 120, in the global case.

This quantification reveals the potential impact of ICT-based interventions in households to mitigate $\mathrm{CO}_{2}$ emissions from the electricity sector. While the overall effect of ICT is a not large relative to the total $\mathrm{CO}_{2}$ reductions necessary to meet the $1.5^{\circ} \mathrm{C}$ target, the total potential reduction in the quantity of $\mathrm{CO}_{2} \mathrm{e}$ emitted by the energy sector is significant. Thus, ICT can clearly add value to the effort at energy system de-carbonization as a part of an "all of the above" transition strategy. In particular, we find that the $\mathrm{CO}_{2} \mathrm{e}$ reduction potential of ICT interventions that bring about behavioural change and energy efficiency in household appliances could have a significant effect on $\mathrm{CO}_{2} \mathrm{e}$ emissions from the electricity sector. However, ICT interventions related to loadshifting and demand response should not be discounted as they can enable more renewable generation sources to be tied to the grid, even if their estimated direct impact on $\mathrm{CO}_{2}$ reduction is low.

\section{Acknowledgements}

The authors gratefully acknowledge funding from the European Union's Horizon 2020 research and innovation programme under the PEAKapp project, grant agreement No. 695945 (http://www.peakapp.eu/). 


\section{References}

[1] European Commission. Commission staff working document, Cost-benefit analyses \& state of play of smart metering deployment in the EU-27. Smart Grids Taskforce. SWD 189. 2014.

[2] Yildiz, B, Bilbao J, Dore J, Sproul AB. Recent advances in the analysis of residential electricity consumption and applications of smart meter data. Applied Energy 2010; 208:402-427.

[3] Leferink F, Keyer C, Melentjev A. Static energy meter errors caused by conducted electromagnetic interference. IEEE Electromagnetic Compatibility Magazine 2016; 5:4, 49-55.

[4] IPCC. Climate Change 2014: Synthesis Report. Contribution of Working Groups I, II and III to the Fifth Assessment Report of the Intergovernmental Panel on Climate Change [Core Writing Team, R.K. Pachauri and L.A. Meyer (eds.)]. IPCC, Geneva, Switzerland.

[5] EEA-European Environment Agency. Achieving energy efficiency through behaviour change: what does it take? 2013; Technical report No 5.

[6] Buildings Performance Institute Europe. Europe's buildings under the microscope. October 2015.

[7] Parker D, Hoak D, Meijer A, Brown R. How much energy are we using? Proceedings of the Summer Study on Energy Efficiency in Buildings 2006; Asilomar, California.

[8] Yu Z, Fung B, Haghighat F, Yoshino M, Morofsky E. A systematic procedure to study the influence of occupant behaviour on building energy consumption. Energy and Buildings 2011; 43:1409-1417.

[9] Rogelj J, Luderer G, Pietzcker RC, Kriegler E, Schaeffer M, Krey V, Riahi K. Energy system transformations for limiting end-of-century warming to below $1.5^{\circ} \mathrm{C}$. Nature Climate Change 2015; 5:6, 519.

[10] European Commission. The Strategic Energy Technology (SET) Plan. Publications Office of the European Union; 2017.

[11] Stern, PC. Toward a Coherent Theory of Environmentally Significant Behavior. Journal of Social Issues 2000; 56: 407-424.

[12] Froehlich J. Promoting energy efficient behaviors in the home through feedback: The Role of HumanComputer Interaction. HCIC Workshop, UW tech note \#09-02-01 2009.

[13] Commission of the European Communities. Commission Recommendation of 9.10.2009 on mobilising Information and Communications Technologies to facilitate the transition to an energy-efficient, low-carbon economy, Brussels. 2009.

[14] European Commission. Commission Staff working document Impact Assessment, Accompanying document to the communication from the Commission to the European Parliament, the Council, the European Economic and Social Committee and the Committee of the Regions Commission Staff working document, Energy Efficiency Plan 2011, Brussels. 2011.

[15] European Commission. Directive 2012/27/EU of the European Parliament and of the Council of 25 October 2012 on energy efficiency, amending Directives 2009/12/EC and 2010/30/EU and repealing Directives 2004/8/EC and 2006/32/EC. 2012.

[16] Berker T. Energienutzung im Heim als soziotechnische Praxis. In: Fischer C, editor. Strom sparen im Haushalt. München, 2008, p. 175-192.

[17] Green LW, Kreuter MW. Health promotion planning: an educational and environmental approach. $3^{\text {rd }}$ ed. Mayfield, Mountain View, California; 1999.

[18] Darby S. Smart metering: What potential for household engagement? Building Research and Information $2010 ; 38: 5,442-457$.

[19] Hargreaves T. The Visible Energy Trial, Tyndall Working Paper 141; 2010. 
[20] Buchanan K, Russo R, Anderson B. The question of energy reduction: The problem(s) with feedback. Energy Policy 2015; 77: 89-96.

[21] Boucher A, Cameron D, Jarvis N. Power to the people: Dynamic energy management through communal cooperation. Proceedings of the Designing Interactive Systems Conference 2012; 612-620.

[22] Hall NL, Jeanneret TD, Rai A. Cost-reflective electricity pricing: Consumer preferences and perceptions. Energy Policy 2016; 95: 62-72.

[23] GreenPocket GmbH. PEAKapp - Deliverable D1.2 documentation of functionalities-system specification. PEAKapp EU Project. 2017.

[24] Sovacool BK, Kivimaa P, Hielscher S, Jenkins K. Vulnerability and resistance in the United Kingdom's smart meter transition. Energy Policy 2017; 109: 767-781.

[25] Chen C, Xu X, Arpan L. Between the technology acceptance model and sustainable energy technology acceptance model: Investigating smart meter acceptance in the United States. Energy Research \& Social Science 2017; 25: 93-104.

[26] Richter L, Pollitt M. Which smart electricity service contracts will consumers accept? The demand for compensation in a platform market. Cambridge Working Papers in Economics 2016.

[27] Sims T. Global athlete: Don’t just map your run, earn points for it. The New York Times, Aug.10, 2012.

[28] Bradley P, Leach M, Torriti JA. A review of the costs and benefits of demand response for electricity in the UK. Energy Policy 2013; 52: 312-327.

[29] McGonigal J. Reality is broken: Why games make us better and how they can change the world. Penguin Press HC. 2011.

[30] Munz U, Schumm P, Wiesebrock A, Allgower F. Motivation and learning progress through educational games, IEEE Transactions 2011; 3141-3144.

[31] Zichermann G, Cunningham C. Gamification by design: Implementing game mechanics in web and mobile apps. O'Reilly Media, Inc. 2011.

[32] Landers RN, Callan RC. Casual social games as serious games: the psychology of gamification in undergraduate education and employee training. In: Ma M, Oikonomou A, Jain L, editors. Serious Games and Edutainment Applications. Springer, London, 2011; p. 399-423.

[33] Locke E, Latham GP. Has goal setting gone wild, or have its attackers abandoned good scholarship? The Academy of Management Perspectives 2009; 23:1, 17-23.

[34] Ordónez LD, Schweitzer ME, Galinsky AD, Bazerman MH. Goals gone wild: How goals systematically harm individuals and organizations, Academy of Management Perspectives 2009; 23:1, 6-16.

[35] Shneiderman B. Designing for fun: How can we design user interfaces to be more fun? Interactions 2004; $11: 5,48-50$

[36] Webster J. Making computer tasks at work more playful: Implications for systems analysts and designers. Proceedings of the ACM SIGCPR conference on Management of information systems personnel 1988; p. 78-87.

[37] Nicholson, S. A user-centered theoretical framework for meaningful gamification, Paper Presented at Games+Learning+Society 8.0 2012; Madison, WI.

[38] Deterding S, Sicart M, Nacke L, O'Hara K, Dixon D. Gamification: Using game-design elements in nongaming contexts, CHI 2011 Gamification Workshop Proceedings 2011; p. 2425-2428.

[39] Deterding S, Sicart M, Nacke L, O'Hara K, Dixon D. Gamification: Toward a definition, CHI 2011 Gamification Workshop Proceedings 2011. 
[40] Hamari J. Transforming Homo Economicus into Homo Ludens: A field experiment on gamification in a utilitarian peer-to-peer trading service. Electronic Commerce Research and Applications 2013; 12:4, 236-245.

[41] European Commission. Horizon 2020 Energy Efficiency Call 2015 Frequently Asked Questions, version 3. 2015.

[42] Laitner JA, Ehrhardt-Martinez K. Examining the Scale of the Behaviour Energy Efficiency Continuum, American Council for an Energy-Efficient-Economy (ACEEE), Congressional Briefing 2009; Washington, DC.

[43] Trotta G. Factors affecting energy-saving behaviours and energy efficiency investments in British households. Energy Policy 2018; 114: 529-539.

[44] Mills BF, Schleich J. Residential energy-efficient technology adoption, energy conservation, knowledge, and attitudes: An analysis of European countries. Energy Policy 2012; 49: 616-628.

[45] Mills BF, Schleich J. Why don't households see the light? Explaining the diffusion of compact fluorescent lamps. Resource and Energy Economics 2012; 32: 363-378.

[46] Eichhammer W, Fleiter T, Schlomann B, Faberi S, Fioretti M, Piccioni N, Lechtenböhmer S, Schüring A, Rusch G. Study on the Energy Savings Potentials in EU Member States, Candidate Countries and EEA Countries 2009. EC Service Contract Number TREN/D1/239-2006/S07.66640.

[47] Druckman A, Chitnis M, Sorrell S, Jackson T. Missing carbon reductions? Exploring rebound and backfire effects in UK households. Energy Policy 2011; 39: 3572-3581.

[48] Freire-Gonzalez J, Font-Vivanco D, Puig-Ventosa I. Economic structure and energy savings from energy efficiency in households. Ecological Economics 2017; 131: 12-20.

[49] Delmas, M. A., Fischlein, M., \& Asensio, O. I. (2013). Information strategies and energy conservation behavior: A meta-analysis of experimental studies from 1975 to 2012. Energy Policy, 61, 729-739.

[50] Schleich J, Faure C, Klobasa M. Persistence of the effects of providing feedback alongside smart metering devices on household electricity demand. Energy Policy 2017; 107: 225-233.

[51] Stromback J, Dromacque C, Yassin MH. The potential of smart meter enabled programs to increase energy and systems efficiency: a mass pilot comparison (Empower Demand). 2011.

[52] Hillemacher L, Nolden C, Bertsch V, Fichtner W. Lastverlagerungspotenziale durch variable Stromtarife Ergebnisse eines Feldtests; Conference Paper, 8. Internationale Energiewirtschaftstagung 2013; Technical University Vienna.

[53] Gilbraith N, Powers SE. Residential demand response reduces air pollutant emissions on peak electricity demand days in New York City. Energy Policy 2013; 59: 459-469.

[54] Smith AM, Brown MA. Demand response: A carbon-neutral resource? Energy 2015; 85: 10-22.

[55] O'Connell N, Pinson P, Madsen H, O'Malley M. Benefits and challenges of electrical demand response: A critical review. Renewable and Sustainable Energy Reviews 2014; 39: 686-699.

[56] Feuerriegel S, Neumann D. Measuring the financial impact of demand response for electricity retailers. Energy Policy 2014; 65: 359-368.

[57] Feuerriegel S, Neumann D. Integration scenarios of Demand Response into electricity markets: Load shifting, financial savings and policy implications. Energy Policy 2016; 96: 231-240.

[58] Goldman C, Reid M, Levy R, Silverstein A. Coordination of Energy Efficiency and Demand Response. US EPA, Lawrence Berkeley National Laboratory. 2010.

[59] Brand HG, Vosloo JC, Bolt GD. Carbon dioxide pollution reduction through load shift projects. 2014 International Conference on the Eleventh industrial and Commercial Use of Energy, p. 1-4. 
[60] Moomaw W, Burgherr P, Heath G, Lenzen M, Nyboer J, Verbruggen A. Annex II: Methodology. In IPCC: Special Report on Renewable Energy Sources and Climate Change Mitigation (ref. page 10).

[61] Moser S, Elbe C, Schmautzer E, Frank F, Muggenhumer G. LoadShift - Lastverschiebung in Haushalt, Industrie, Gewerbe und kommunaler Infrastruktur Potenzialanalyse für Smart Grids. Berichte aus Energie- und Umweltforschung 2015.

[62] Nilsson A, Stoll P, Brandt N. Assessing the impact of real-time price visualization on residential electricity consumption, costs, and carbon emissions. Resources, Conservation and Recycling 2017; 124: 152-161.

[63] AlFaris F, Juaidi A, Manzano-Agugliaro F. Intelligent homes' technologies to optimize the energy performance for the net zero energy home. Energy and Buildings 2017; 153: 262-274.

[64] Lu J, Sookoor T, Srinivasan V, Gao G, Holben B, Stankovic J, Field E, Whitehouse K. The smart thermostat: Using occupancy sensors to save energy in homes. Proceedings of the 8th ACM Conference on Embedded Networked Sensor Systems, ACM, 2010; 211-224.

[65] Meyers RJ, Williams ED, Matthews HS. Scoping the potential of monitoring and control technologies to reduce energy use in homes. Energy and Buildings 2010; 42:5: 563-569.

[66] Cosar-Jorda P, Buswell RA, Mitchell V. Identifying the opportunities for ICT based energy demand reduction in family homes. Loughborough University Institutional Repository 2015; EEDAL Project: Energy Efficiency in Domestic Appliances and Lighting, Lucerne-Horw, Switzerland.

[67] Statista. Smart home in Europe. https://www.statista.com/outlook/279/102/smart-home/europe\# ; 2017, [last accessed July 12, 2018].

[68] Reichl, J, Kollmann A. The baseline in bottom-up energy efficiency and saving calculations - A concept for its formalisation and a discussion of relevant options. Applied Energy 2010; 88: 422-431.

[69] Covenant of Mayors. Technical annex to the SEAP template instructions document: the emission factors. http://www.covenantofmayors.eu/IMG/pdf/technical_annex_en.pdf ; 2014, [last accessed July 12, 2018].

Highlights

- The ways that ICT can be used in the household electricity sector are summarized

- Proven effects of ICT on household electricity use are compiled

- Potential of ICT in electricity sector to reduce greenhouse gases is assessed 